\title{
METODOLOGI TAFSIR ALQURAN BERBAHASA BUGIS KARYA AGH MUHAMMAD ABDUH PABBAJAH
}

\section{The Interpretation Method of Holy Quran in Bugis Language The Work of AGH Muhammad Abduh Pabbajah}

\author{
M. Nasri Hamang \\ Sekolah Tinggi Agama Islam Negeri Parepare \\ Perumahan Soreang Indah Permai Blok B2/19 Parepare \\ Email : nasrihamang@gmail.com
}

Naskah diterima tanggal 12 September 2012. Naskah direvisi tanggal 18 Oktober 2012. Naskah disetujui tanggal 7 Desember 2013

\begin{abstract}
Abstrak
Tulisan ini membahas profil metodologi tafsir Alquran al-Karim berbahasa daerah Bugis karya AGH (Anre Gurutta Haji) Muhammad Abduh Pabbajah. Tafsir tersebut menjadi penting bukan hanya karena penulisnya salah seorang ulama besar di Sulawesi Selatan (yang biografinya masuk dalam Ensiklopedi Islam), melainkan secara akademik, metodologi yang ditempuhnya memiliki kekhasan yang membedakannya dengan umumnya metodologi yang ditempuh para mufassirin, baik mutaqaddimin maupun mutaakhkhirin. Salah satu yang menonjol dari kekhasan itu ialah sistematikanya yang dimulai dari Juz 30-Juz 'Amma (yang biasa distilahkan dengan Alquran Kecil) ke Juz 1 sampai 29 (yang biasa diistilahkan dengan Alquran Besar). Dalam hal kekhasan itu sendiri pun, ditafsirkannya secara sedemikian mudah untuk dipahami oleh masyarakat (umat Islam suku Bugis). AGH Muhammad Abduh Pabbajah menempuh seperti itu-dalam arti-dengan lebih mendahulukan Juz Amma dengan pertimbangan, surah-surah dalam Juz 'Amma lebih sering dijadikan oleh masyarakat muslim sebagai pappanguppu dalam salat. Di samping itu, kandungan surah-surah dalam Juz 'Amma adalah berkenaan masalah teologi sebagai ajaran agama yang prinsipil.
\end{abstract}

Kata kunci: AGH Muhammad Abduh Pabbajah, tafsir berbahasa Bugis dan metodologi tafsir

\begin{abstract}
This paper accounts the methodology of holy Quran interpretation in Bugis language by Muhammad Abduh Pabbajah. His interpretation method is important not only because he is one of the popular Muslim scholars "ulama" in South Sulawesi, but also academically his used method has particular characteristic which distinguishes from common interpreters "mufassirin", even both in the early era and in the recent era. One of the prominent characteristics is his systematic in interpreting the holy Quran which was started from for the last juz "Juz 'Amma" to the juz one and until the juz 29. In its characteristic, his interpretation is easily understood specially for Bugis Muslims. Muhammad Abduh Pabbajah considered interpreting the holy Quran from the last juz because the Surahs in it are always recited by the people in five times praying. In addition, the contents of the Surahs are about theology as the principles of Islamic teaching.
\end{abstract}

Keywords: AGH Muhammad Abduh Pabbajah, Bugis interpretation, interpretation method

\section{PENDAHULUAN}

A lquran diturunkan Allah untuk menjadi petunjuk hidup bagi manusia, yaitu petunjuk yang menerangkan tentang jalan kebaikan dan jalan keburukan yang harus dilalui manusia agar memperoleh keselamatan dan kebahagiaan hidup di dunia dan di akhirat (QS. Al Baqarah (2): 185). Akan tetapi alquran sebagai petunjuk hidup, Allah memformulasikannya dengan sifat global, yaitu bersifat menerangkan garis-garis besarnya saja. Karena itu, supaya menjadi petunjuk hidup yang terang, Allah mengamanahkan Nabi 
Muhammad untuk menerangkannya lebih lanjut (QS. An Nahl (16): 44 dan 64 ). Dengan demikian, Nabi Muhammad secara langsung bertindak sebagai mufassir pertama.

Sepeninggal Nabi Muhammad, hal mana keadaan manusia makin berkembang yang diiringi tuntutan keterangan hal-ihwal islamiah yang makin berekembang pula, maka aktivitas tafsir pun ikut berkembang. Dihitung dari masa Nabi Muhammad hingga sekarang, aktivitas tafsir, khususnya dilihat dari segi kodifikasinya, menurut M. Quraish Shihab telah melalui 3 (tiga) periode. Periode pertama; masa Rasulullah, sahabat dan permulaan tabi'in; masa mana tafsir belum belum tertulis, tetapi periwayatan tersebar secara lisan. Periode kedua; bermula pada masa pemerintahan Umar bin Abd. Aziz (99-101 H), yang hal mana tafsir bergabungan dengan penulisan hadis secara resmi. Periode ketiga; dimulai dengan penyusunan kitab-kitab tafsir secara khusus dan berdiri sendiri, yang diduga kuat dilakukan oleh al-Farra (w. 207 H) demgan kitabnya, Ruhul Ma'ani (Nata, 2003: 167-168).

Dalam masa abad XX, aktivitas tafsir tidak hanya berkembang di Timur Tengah dan dalam bahasa Arab, melainkan telah menyeberang ke aneka benua lainnya dan dalam bahasa non-Arab. Lahirlah kemudian tafsir berbahasa Inggris, berbahasa Indonesia dan sebagainya; serta bahkan dalam bahasa lokal seperti antara lain bahasa Jawa, bahasa Sunda, bahasa Bugis - karangan AGH Muhammad Abduh Pabbajah - yang menjadi subyek tulisan ini.

\section{PEMBAHASAN}

\section{Sekelumit AGH Muhammad Abduh Pabbajah}

AGH Muhammad Abduh Pabbajah yang lebih masyhur dipanggil Kali Pabbajah adalah salah satu ulama besar di Sulawesi Selatan dalam bidang tafsir. Ia tergolong ulama generasi ketiga Sulawesi Selatan bersama antara lain AGH Muhammad Yunus Martan (alm), AGH Abd. Radjab Malili (alm) diurut dari generasi pertama, AGH Muhammad As'ad (alm), AGH Ahmad Bone (alm), AGH Muhammad Thahir Imam Lapeo (alm) dan lainlain; dan generasi kedua, AGH Abd. Rahman Ambo Dalle Pinrang (alm), AGH Daud Ismail - Soppeng (alm), AGH Yusuf Hamzah - Parepare (alm), AGH Djuanid Sulaiman - Bone (alm) dan lain-lain.(Muiz Kabry: 2011).

Ia lahir tahun $1337 \mathrm{H}$ di Allakuang, Sidenreng Rappang dan wafat di Parepare tahun 1430 H/2010 $\mathrm{M}$ atau dalam usia 94 tahun. Ia berguru ilmu agama pad AGH Muhammad As'ad (Pendiri Perguruan Islam As'adiyah, Sengkang) selama 10 (sepuluh) tahun. Dengan ilmu agama yang diperoleh dari AGH Muhammad As'ad, kemudian pulang ke Sidenreng Rappang mendirikan Perguruan Islam, lalu ke Cabenge, Soppeng yang keduanya ditutup oleh pemerintah kolonial (karena ia dinilai oleh pemerintah kolonial menghembuskan semangat merdeka kepada murid-muridnya). Kemudian pulang lagi ke Sidenreng Rappang dan diangkat menjadi Kadi (Kali) Sidenreng merangkap sebagai Matoa (jabatan setingkat camat) Allakuang. Dari Kadi Sidenreng lalu diangkat menjadi Kepala Urusan Agama Kabupaten Parepare serta terakhir menjadi Dekan Fakultas Tarbiyah IAIN Alauddin di Parepare (1967-1984).

AGH Muhammad Abduh Pabbajah yang sejak tahun 1951 sampai wafatnya menetap di Kota Parepare, selain dikenal sebagai ulama besar, dikenal pula sebagai mubalig ulung oleh masyarakat Parepare dan sekitarnya (atau Ajattappareng). Sebagai mubalig ia tergolong sosok yang berani mengemukakan Islam apa adanya. Saat sedang bertablig tergambar bahwa ia tidak terbayangbayangi oleh superiotas pihak mana pun termasuk penguasa. Tampil dengan penuh percaya diri, dengan suara lantang dan ulasan yang gamblang tanpa mengesankan rasa ragu sedikit pun. Ia seperti mengaktualisasikan firman Allah S. al-Maidah (5) : $67 \mathrm{sbb}$ :

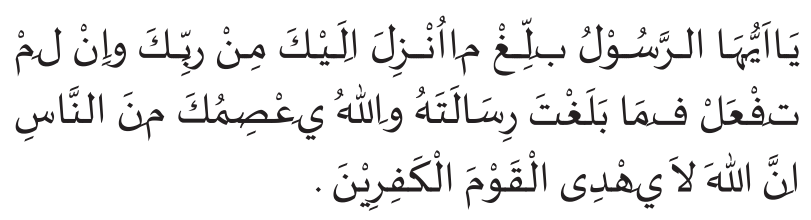

Hai Rasul, sampaikanlah apa yang diturunkan kepadamu dari Tuhanmu; dan jika kamu tidak kerjakan (apa yang diperintahkan itu, berarti) kamu tidak menyampaikan amanat-Nya; Allah memelihara kamu dari (gangguan) manusia. Sesungguhnya Allah tidak memberi petunjuk kepada orang-orang kafir.

Di samping sebagai ulama dan mubalig, ia pun aktivis orpol (organisiasi politik) dan ormas (organisasi massa) Islam. Ia aktivis PPP (Partai Persatuan Pembangunan), SI (Syarikat Islam) dan DDI (Daru Da’wah Wal Irsyad). Untuk orpol ia aktif sebagai pengurus dan jurkam (juru kampanye) PPP; 
dan untuk ormas Islam, ia mendirikan Pesantren Al-Furqan DDI di Kota Parepare.

Di samping itu pula, ia tekun dalam dunia tulis-menulis. Adapun karya tulisnya yang diterbitkan adalah kitab tafsir Tafsir Al-Qur'an ulKarim Berbahasa Daerah Bugis, Ushul al-Tafsir, dan kitab fikih Ash-Shalatu Miftahu Kulli Khaerin. Dua kitab yang disebut terakhir ditulis dalam bahasa Arab.

\section{Latar Belakang Tafsir}

AGH Muhammad Abduh Pabbajah menyusun tafsirnya dilatarbelakangi 2 (dua) faktor sebagai berikut :

Pertama, spirit dan komitmennya yang tinggi untuk mengajarkan dan memasyarakatkan pemahaman dan pengamalan nilai-nilai Alquran. Ia berkeyakinan penuh bahwa hanya dengan pemehaman dan pengamalan nilai kandungan Alquran yang baik oleh umat Islam, hidup dan kehidupan umat Islam dapat menjadi lebih baik pula. Karena begitu concern dan fokusnya pada keyakinannya itu, ia meminta berhenti sebagai Kepala Urusan Agama Kabupaten Parepare, untuk kemudian mendirikan Perguruan Islam di Allakuang, yang beliau sendiri langsung menfasilitasi akan segala kebutuhannya.

Spirit, komitmen dan keyakinannya tersebut termotivasi hadis Nabi saw:

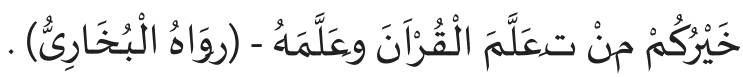

Orang yang yang paling baik di antara kalian, yang mempelajari Alquran dan mengajarkannya - (H. R. al-Bukhari). (Pabbajah, 1977)

Sehubungan dengan itu, pesan beliau yang paling penting terhadap umat Islam adalah:

\section{Engkalaloki mennang manggurui akorangnge; bacana, betttuanna nenniyya apasilennerenna (Hendaklah kalian mempelajari Alquran; bacaan, arti dan pengamalannya) (Pabbajah, 1977).}

Kedua,realisasi dari rekomendasi musyawarah ulama se Sulawesi Selatan pada pertengahan tahun 1960-an di Makassar, yang salah satu isinya adalah agar para ulama melakukan penerjemahan dan penafsiran Alquran tertulis dalam bahasa daerahnya masing-masing di mana tempatnya berkiprah sebagai ulama.

Sepulang dari musyawarah ulama, AGH Muhammad Abduh Pabbajah segera melakukan penerjemahan dan penafsiran Alquran sampai akhirnya pada awal tahun 1970-an rampung seluruh 30 juz, sekaligus diterbitkan menjadi sebuah kitab tafsir dengan nama Tafsir Al-Qur'an al-Karim Berbahasa Daerah Bugis. Kitab tafsir tersebut telah beredar luas di kawasan daerah Bugis Ajattappareng (Barru, Parepare, Pinrang Sidenreng Rappang dan Enrekang). Namun kitab ini telah lama tidak terbit sehingga cukup sulit mendapatkannya, sekalipun hanya untuk beberapa jilid (juz), apatah lagi seluruhnya.

Selain melakukan penerjemahan dan penafsiran secara kitabah (tertulis), ia pun melakukannya secara kalam (lisan) dalam bentuk ceramah/pengajian. Secara kalam ini dilakukan di hadapan jamaah dan di Studio Radio Suara Masjid Agung Parepare, yang menurutnya sampai sekarang telah menamatkan penerjemahan dan penafsiran sebanyak 3 (tiga) kali, bahkan sedang yang ke-4 (empat) kalinya, yang memasuki surah al-Ahzab.

Aktivitas penerjemahan yang mungkin bersifat lebih meluas dan mendalam dilakukannya secara sewaktu-waktu, yaitu ketika orang tertentu yang datang ke kediamannya untuk meminta penjelasan yang lebih jauh mengenai sesuatu permasalahan keagamaan.

\section{Orientasi Tafsir}

Alquran adalah petunjuk hidup yang sempurna (QS. Al Maidah (5): 3 ). Petunjuk yang mencakup kebaikan hidup duniawi dan ukhrawi. Di dalamnya terdapat petunjuk akidah, akhlak, hukum dan isyarat ilmiah secara menyeluruh. Karena itu, menafsirkan Alquran bukan sesuatu yang mudah. Seorang yang melakukan penafsiran, betapa pun luas ilmu dan daya intelektualnya (seperti yang telah bergelar mufassir semisal Ibn Jarir al-Thabari pun, guru besar para ahli tafsir - julukan yang diberikan M. Quraisy Syihab untuknya), tidak mampu menafsirkan Alquran secara mencakup seluruh aspek kebaikan duniawi dan ukhrawi di dalamnya. Namun demikian, Alquran sebagai petunjuk hidup, seseorang sesuai dengan ilmu alat tafsir yang dimilikinya dan faktor-faktor yang ada pada dirinya yang menunjukkan batas kesanggupannya, harus berupaya melakukan kegiatan tafsir, sebab dari penafsiranlah, Alquran berfungsi menjadi petunjuk hidup bagi manusia. Dari penafsiranlah dipahami 
hukum-hukum agama, falsafah-falsafah duniawiah dan proyeksi-proyeksi ukhrawiah.

Demikian luas sifat petunjuk Alquran berserta ruang tafsir yang dibangunnya, maka ulama (dalam pengertian konvensional), mungkin termasuk di Asia Tenggara terutama di Indonesia, melakukan kegiatan penulisan tafsir dengan berorientasi pada kebutuhan lokal, yakni sesuai keperluan mendasar masyarakat yang dihadapinya. Dan seperti yang disaksikan bahwa sampai sekarang umat Islam Indonesia, umumnya masih memerlukan penafsiran dalam soal-soal akidah, akhlak dan hukum-hukum yang bersifat normatif, dalam arti belum memerlukan penafsiran dalam soal-soal kontemporer, seperti kedokteran, aktivitas di angkasa luar dan lain-lain. Karena itu, kitabkitab tafsir yang dikarang ulama Asia Tenggara, termasuk Indonesia bersifat sangat sederhana sesuai kesederhanaan tuntutan kehidupan umat Islam Asia Tenggara, termasuk Indonesia di seputaran soal-soal akidah, akhlak dan hukum-hukum yang bersifat normatif itu. Dalam hubngan ini, T. M. Hasbi Ash-Shiddieqy mengatakan, kita harus menyusun tafsir yang sederhana, yang di dalamnya kita terangkan dengan ringkas akan hal-hal yang dapat menumbuhkan jiwa membesarkan Allah dalam diri para mukmin dan memalingkannya dari kejahatan serta menariknya kepada kebaikan (Ash Shiddiqy, 1966: 97-98).

Tafsir yang sederhana dan merupakan tuntutan penting bagi mayoritas umat Islam Indonesia adalah misalnya penafsiran ringkas, mendalam dan gamblang tentang awal-awal surah al-Mu'minun (23) ayat 1-11. Penafsiran terhadap ayat-ayat tersebut, nampak amat penting, mengingat masih banyaknya individu muslim Indonesia yang memandang remeh perintah-peruntah wajib salat, ucapan-ucapan berguna, membayar zakat, menghindari perzinahan dan memelihara amanah, yang ksesemuanya merupakan persyaratan untuk masuk surga sebagai tujuan hakiki dari perjalanan hidup menusia.

AGH Muhammad Abduh Pabbajah tampak bahwa dalam rangka pertimbangan tersebut pulalah, ia pun menempuh orientasi tafsir waqii atau tafsir fungsional. Ketika membaca tafsir atau mendengar pengajian tafsir/tablignya, terasa sekali betapa ia mendambakan umat Islam (di daerah Bugis) yang paham akan pokok-pokok agamanya - dalam hal ini -, Tuhannya, Nabinya, eksistensi hidupnya, eksistensi dunia, eksistensi akhirat, kewajiban dan larangan keagamaan dan lain-lain, yang dengannya dapat menjadi umat Islam yang taat, yang dampak positifnya bukan hanya mendatangkan hidup nikmat di akhirat sebagaimana kesan selama ini (bahwa Islam agama akhirat), melainkan lebih awal dapat dirasakan di dunia.

\section{Sistematika Tafsir}

AGH Muhammad Abduh Pabbajah menempuh sistematika tafsir berbeda dengan yang ditempuh para mufassir, terutama mutaqaddimin (di negara-negra Arab). Para mufassir mutaqaddimin menempuh sistematika menurut nomor urut surah, yakni dari nomor urut satu, yang dilanjutkan dengan nomor urut dua, kemudian dilanjutkan lagi dengan nomor urut tiga dan seterusnya sampai nomor urut terakhir (114; atau mulai dari surah al-Fatihah, kemudian surah al-Baqarah, kemudian surah Ali Imran dan seterusnya hingga surah al-Nas). Lain halnya AGH Muhammad Abduh Pabbajah, khususnya surah-surah dalam Juz 'Amma atau yang popular disebut Korang Biccu, (yang terdiri dari 37 surah), ia menyusunnya berdasarkan urutan surah dalam Korang Biccu itu.

Sebagai contoh dapat dilihat dalam Kitab Tafsir Jilid V yang memuat sebanyak 6 (enam) surah, yaitu surah al-A'la, surah alp-Gasyiyah, surah al-Fajr, surah al-Balad surah al-Syams dan surah al-Lail, ia memulai menafsirkan dari surah al-Lail, kemudian surah al-Syams, kemudian surah al-Fajr, kemudian surah al-Gasyiyah, dan kemudian surah al-A'la; dan tiap surah yang ditafsirkan diberi nomor tanda urut, misalnya surah al-Lail diberi nomor anda urut 24, surah al-Syams diberi nomor tanda urut 25 dan sebagainya (Pabbajah, 1977: 3 dan 8), sehingga seolah-olah surah al-Lail adalah nomor surah urutan ke-24 dan surah al-Syams adalah nomor surah urutan ke-25 dalam Alquran, padahal masing-masimg adalah urutan ke-92 dan ke-91.

AGH Muhammad Abduh Pabbajah memilih sistematika tersebut, menurut penulis adalah dengan pertimbangan bahwa surah-surah dalam Juz 'Amma atau atau dalam Korang Biccu itu, lebih banyak dipilih umat Islam menjadi pappanguppu dalam setiap melaksanakan salat. Sebagai surah yang lebih banyak dipilih menjadi pappanguppu, agar pelaksanaan salat lebih khusyuk - khususnya kerika membaca surah untuk pappanguppu -, maka amat perlu diketahui arti dan maksudnya. Dalam konteks itu, salah satu sarana paling efektif untuk mengantar umat Islam mengetahui arti dan maksud surah-surah dalam Juz 'mma itu ialah dengan mengusahakan sebuah tafsir yang dapat dibaca dan 
dipahaminya. Karena itu, AGH Muhammad Abduh Pabbajah mendahulukan menafsirkan surah-surah dalam Juz Amma, lantaran menurutnya surahsurah dalam Juz Amma lebih mendesak dibanding surah-surah dalam Korang Lompoe untuk diketahui arti dan maksudnya oleh umat Islam.

\section{Gaya Tafsir}

AGH Muhammad Abduh Pabbajah dalam menafsirkan Alquran bersifat penafsiran ringkas (atau apa yang dalam bahasa Bugis disebut bettuang atau tapessere rippe) dengan gaya pragrafistik. Ia mencermati surah akan berapa gerangan ide utama yang terdapat di dalamnya, lalu ditafsirkannya perparagraf. Setelah ditafsirkannya, ia biasanya menutupnya dengan sebuah rumusan hikmah (pelajaran), yang ia sebut dalam Bugis akkeguna riyalae pole surae (manfaat yang diperoleh dari surah yang bersangkutan).

Contoh penafsirannya terhadap surah ke-92 - surah al-Lail -. Surah ke-92 surah al-Lail - yang terdiri atas 21 ayat, ia membaginya ke dalam 6 (enam) paragraf dengan urutan sebagai berikut: Ayat 1 sampai 3 (paragraf I), ayat 4 (paragraf II), ayat 5 sampai 11 (paragraf III), ayat 12 sampai 13 (paragraf IV), ayat 14 sampai 16 (paragraf V) dan ayat 17 sampai 21 (paragraf VI) (Pabbajah, 1977: 4-7). Keenam paragraf tersebut ditutupnya dengan 5 (lima) rumusan hikmah (Pabbajah, 1977: 4). Perumusan hikmah disarikan dari setiap paragraf. Karena itu jumlah paragraf (yang 6) relatif sebanding dengan jumlah rumusan hikmah (yang 5).

\section{Jenis Tafsir}

AGH Muhammad Abduh Pabbajah menyusun tafsirnya dengan didukung oleh referensi dari kitab-kitab tafsir jenis bil-ma'tsur dan bir$r a ' y i$. Menurut keterangan beliau, kitab-kitab tafsir yang menjadi rujukannya, antara lain tafsir Jalalain (lugawi), tafsir Ibn Katsir (bil-ma'tsur), tafsir alManar (bir-ra' $y i$ ), tafsir al-Syaukani (gabungan bilma'tsur dan bir-ra' $y i$ ). Jadi dapat dikatakan bahwa substansi kandungan penafsirannya, secara umum merupakan penggabungan saripati dari tafsir jenis bil-ma'tsur dan bir-ra' 'yi.

Namun demikian, berujuk pada praksis penafsirannya, maka dapat juga dikatakan, bahwa untuk hal-hal tertentu, ia menempuh jenis bir-ra' $y i$. Misalnya dalam menafsirkan ayat 3 (tiga) surah

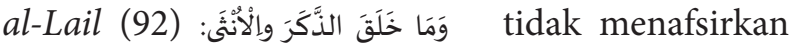

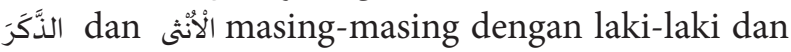
perempuan dalam segi biologis (kelaminnya) saja, tetapi menafsirkan lebih jauh, mencakup aspek psikilogisnya, jiwa atau sifat-sifat (Pabbajah, 1977: 5). Jadi maksudnya, antara laki-laki dan perempuan tidak hanya berbeda dalam segi bentuk biologis, tetapi berbeda pula dalam segi karakter dan tingkah laku. Dengan demikian, jenis tafsir susunan AGH Muhammad Abduh Pabbajah adalah sebuah deskripsi global dari tafsir bil ma 'tsur dan bir-ra' $y i$.

\section{Corak Tafsir}

AGH Muhammad Abduh Pabbajah tampak bahwa demi pertimbangan parktis dan sedrhana, seperti pertimbangan umumnya penyusun tafsir orang Indonesia lainnya, yang berorientasi hajat pokok tuntutan keagamaan umat Islam seputar dasar-dasar akidah, dasar-dasar syariah dan dasardasar akhlak, sehingga ia menempuh corak tafsir dengan apa yang disebut sekarang corak atau metode ijmali.(Nata, 2003: 172).

Hal itu tampak sekali dalam menafsirkan setiap ayat, bahkan terhadap sejumlah ayat, ia langsung menarik kandungan utama ayat yang ia perkirakan dapat menjadi nasihat atau pelajaran bagi umat Islam. Dengan caranya ini dapat dikatakan, bahwa corak ijmali yang ditempuhnya berbeda dengan yang ditempuh para mufassir mutaqaddimin. Ia menempuh corak ijmali yang bersifat ringkas sesuai kebutuhan dan tingkat kemampuan pemahaman umat Islam Bugis.

\section{Ciri Khas Tafsir}

Tafsir susunan AGH Muhammad Abduh Pabbajah tampak mempunyai ciri khas yang menjadi kekuatan efektifnya untuk menuntun umat Islam. Ciri khasnya terletak pada kemampuan AGH Muhammad Abduh Pabbajah memilih kata-kata/ istilah bahasa Bugis yang relatif sesuai dengan rasa bahasa dan budaya orang-orang Islam di daerah Bugis. Misalnya dalam menafsirkan ayat 11 dan 12 dalam surah al-Balad (90) :

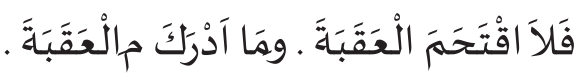

Maka tidakkah sebaiknya (dengan hartanya itu), ia menempuh jalan yang mendaki lagi sukar (11). Tahukah kamu apakah jalan yang mendaki lagi sukar itu? (12).

Umumnya ulama Indonesia yang menulis kitab tafsirnya dalam bahasa Indonesia menerjemahkan atau menafsirkan kata الْعََََ dengan jalan mendaki. Beberapa pakar Islam mengemukakan dalam 
tulisannya dengan arti atau tafsir jalan mendaki lagi sukar (termasuk para ulama tim penuilis terjemah/ tafsir al-Qur'an Kementerian Agama R. I.). Akan tetapi AGH Muhammad Abduh Pabbajah sebagai orang Bugis yang meninginkan penafsiran untuk kebutuhan orang-orang Bugis, ia menerjemahkan atau menafsirkan kata الْعََََة dengan pasunna decengge.

Bagi orang Bugis, menerjemahkan الْعََََ dengan jalan mendaki lagi sukar (yang kalau diterjemahkan ke dalam bahasa Bugis berarti tuppung mawatang), sulit atau tidak dapat memhami maksudnya sesegera mungkin, bahkan boleh jadi secara spontanitas lebih memaknai ke dalam pengertian yang berkebalikan dari arti atau maksud kata الَْقَبََ yang sebenarnya. Dengan terjemah jalan mendaki lagi sukar, secara psikologis, tidak bersifat spontan mendorong umat Islam untuk mempertanyakan seperti apa الْعَقَبَة itu, sebab umumnya orang tidak menyukai sebuah kondisi jalan yang berpostur mendaki lagi sukar untuk ditempuh.

Tetapi dengan menerjemahkan pasunna decengnge (bentuk kebaikan yang bekualitas, manfaatnya kekal dan salah satu paling disenagi Allah), maka orang-orang Bugis spontan dapat memahaminya, dan dengan demikian akan tertarik mempertanyakan lebih lanjut, amal kebaikan seperti apa yang termasuk الْعََََة itu. Jadi terjemah pasunna decengnge mempunyai kekuatan psikologis dalam memompa semangat umat Islam untuk mempertanyakan makna sekaligus bentuk-bentuk amal kongkret dari konsep الْعَقَبَ itu.

\section{PENUTUP}

AGH Muhammad Abduh Pabbajah diukur secara kultur Indonesia memenuhi syarat disebut dengan ulama besar (di Sulawesi Selatan), yaitu ia mengarang kitab, membina perguruan, dan aktif bertablig. AGH Muhammad Abduh melakukan aktivitas tafsir dilatarbelakangi oleh amanah ilmu yang dimilikinya untuk diamalakan dalam rangka pencerdasan dan pengembangan umat Islam. Tafsir AGH Muhammad Abduh Pabbajah yang ia sendiri tidak pernah menamainya akan suatu jenis atau corak, yang belakangan muncul bermacam-macam peristilahan terhadap tafsir, tetapi ia menyusun tafsirnya sesuai latar belakang ilmunya dan kebutuhan umat Islam (ras berbahasa daerah Bugis), namun mencermati tafsirnya secara perspektif akademik, maka ia dapat digolongkan ke dalam jenis atau corak menurut istilah-istilah tafsir yang populer saat ini.
Tafsir AGH Muhammad Abduh Pabbajah, secara orientasi, bervisi tafsir fungsional; secara sistematika, menempuh prioritas surah-surah dalam Juz Amma; secara jenis, merupakan deskripsi dari bil-ma'tsur dan bir-ra'yi; secara corak, berwarna ijmali; dan secara ciri khas, akurat dalam memilih peristilahan dalam bahasa Bugis. Tafsir AGH Muhammad Abduh Pabbajah termasuk tafsir yang mandiri dan bebas dari pengaruh pihak mana pun. Ini memvalidasi tafsirnya dapat dipertanggungjawabkan, baik secara ilmiah (metodologis akademik) maupun akidah (teologi islamiah).

\section{UCAPAN TERIMA KASIH}

Ucapan terima kasih tak terhingga disampaikan kepada Dewan Redaksi Jurnal Alqalam yang memuat tulisan ini dalam penerbitannya. Keluarga dan rekan-rekan yang telah membantu menyumbangkan buah pikiran dan ide-idenya demi penyempurnaan tulisan ini.

\section{DAFTAR PUSTAKA}

\section{al-Qur'an al-Karim}

Ahmad, Abd. Kadir. 2009. Ulama Bugis. Makassar: Penerbit Indobis Publishing.

As'ad, Muhammad dkk. 2011. Buah Pena Sang Ulama. Jakarta: Orbit.

Ash-Shdiieqy, T. M. Hasbi, 1966. Tafsir Al-Bayan, Jilid I; Bandung : Al-Ma'arif.

Departemen Agama R. I., 1971. Al-Qur'an dan Terjemahnya; Jakarata: Yayasan Penyelenggara Penterjemah/Pentafsir AlQur`an.

Ensiklopedi Islam, Jilid II, Edisi Suplemen, 2003. Cet. IX; jakarta: Ichtiar Baru van Hoeve.

Muiz Kabry, Abd. 2006. Darul Da'wah Wal Irsyad (DDI) dalam Simpul Sejarah Kebangkitan dan Perkembangan. Parepare: DDI.

Nata, Abuddin, 2003. Metodologi Studi Islam, Cet. I; Jakarta : Raja Grafindo Persada.

Pabbajah, M. Abduh. 1397/1977. Tafsir Al-Quran alKarim Berbahasa Daerah Bugis, Jilid V (Tafsir Juz 'Amma), Cet. III; Parepare : Pabbajah.

Zuhri, Saifuddin. 1980. Searah Kebangkitan Islam dan Perkembangannya di Indonesia. Bandung: PT. Al Ma’arif. 